\title{
Effects of Brief Mindfulness-Based Interventions on Health-Related Outcomes: a Systematic Review
}

\author{
Ana Howarth ${ }^{1}$ (D) $\cdot$ Jared G. Smith ${ }^{1} \cdot$ Linda Perkins-Porras ${ }^{2} \cdot$ Michael Ussher $^{1,3}$
}

Published online: 31 May 2019

(C) The Author(s) 2019

\begin{abstract}
Objectives Traditional mindfulness-based interventions (MBIs) have been applied successfully across many populations. The time commitment for these programs is often a barrier, and while brief MBIs have become popular, the impact of these on healthrelated outcomes is unclear as they have not yet been reviewed.

Methods A search of databases, including Medline, Embase, and PsycINFO, was conducted with qualitative and case studies being excluded. Findings were summarized using a narrative approach for all studies that met the inclusion criteria.

Results With one exception, all 85 studies that were included were randomized controlled trials and were relatively robust methodologically. Seventy-nine reported significant positive effects on at least one health-related outcome and over a quarter targeted a clinical population. The majority of studies focused on psychological outcomes, such as anxiety and depression, as well as emotion regulation, stress, and cognitive outcomes.

Conclusions Despite heterogeneity of outcomes across studies, there is evidence that brief MBIs can impact numerous healthrelated outcomes, after only one session and with interventions as brief as $5 \mathrm{~min}$. These interventions have the potential to be the initial steps leading to sustainable and positive health outcomes.
\end{abstract}

Keywords Mindfulness $\cdot$ Brief interventions $\cdot$ Systematic review $\cdot$ Health outcomes

Mindfulness can be defined as an approach to experiencing everyday life by turning attention and awareness to the present moment without judgment (Kabat-Zinn 2006). Despite its Buddhist origins, mindfulness is now often a secular practice and is easily accessible to many, whether practiced in an individual's home or by attending a class (Hyland 2016). Mindfulness encompasses the key therapeutic concepts of acceptance, compassion, and detachment (Bogosian et al. 2016;

Electronic supplementary material The online version of this article (https://doi.org/10.1007/s12671-019-01163-1) contains supplementary material, which is available to authorized users.

Ana Howarth

ahowarth@sgul.ac.uk

1 Population Health Research Institute, St George's, University of London, London, UK

2 Institute of Medical and Biomedical Education, St George's, University of London, London, UK

3 Institute for Social Marketing and Health, University of Stirling, Stirling, UK
Desrosiers et al. 2013; Pinto-Gouveia et al. 2014). As a therapy, the practice of mindfulness is predominately based on a chronic illness program that was originally "formalized" as mindfulnessbased stress reduction (MBSR), a treatment for illness-related stress. More recently, the more cognitive treatment of mindfulness-based cognitive therapy (MBCT) has emerged (Teasdale et al. 2000), principally as a treatment for depression.

Over the years, mindfulness-based therapies (most commonly MBSR and MBCT) have been applied successfully to a range of clinical populations (Gotink et al. 2015) including patients recovering from cancer, patients with low back pain, and patients with general anxiety disorders (Cherkin et al. 2016; Evans 2016; Johns et al. 2015). This research has cumulated into a solid foundation of evidence supporting the use of mindfulness for clinical health conditions, as well as for the management of non-clinical conditions such as everyday stress and mood disturbances (Cavanagh et al. 2014; Hilton et al. 2017; Krolikowski 2013; Lakhan and Schofield 2013; Strauss et al. 2014).

MBSR and MBCT programs are similar, in that they last 8 weeks and require daily practice, along with weekly group sessions. These programs require a high-level commitment 
from both the participant and facilitator and this has potentially been a barrier for many who may benefit from a mindfulness-based approach (Chen et al. 2014; Craigie et al. 2016; Crane and Kuyken 2013). Thus, recent studies have sought to explore the effects of mindfulness-based interventions (MBIs) that are briefer and less intense. Often comprised of a single key element of the mindfulness approach (e.g., acceptance or compassion), these interventions are commonly packaged as a quick and easy self-management tool and are backed by evidence that even small behavior changes can impact complex health outcomes (Davis et al. 2015; Hill et al. 2003; Stroebele et al. n.d.). However, currently, no reviews address brief MBIs across health-related outcomes in general. There is a subsequent knowledge gap with regard to how much mindfulness is needed to be effective, for whom and for what health-related outcomes. We conducted a comprehensive systematic, narrative review of studies intended to assess the effects of brief MBIs on mental or physical healthrelated outcomes.

\section{Method}

This review was conducted according to the Preferred Reporting Items for Systematic Reviews and Meta-Analyses (PRISMA) statement (Moher, Liberati, Tetzlaff, Altman, and PRISMA Group 2009) and is registered with PROSPERO (registration 2016:CRD42016045644).

\section{Study Selection}

The selection of studies is illustrated in Fig. 1, using the PRISMA flow diagram (Moher et al. 2009). The search identified 3342 papers, which were screened for eligibility. After removal of duplicates and those deemed ineligible, 152 fulltext articles were retrieved and read in full by two reviewers (AH and MU). Hand searches identified a further four papers which were read in full. A total of 85 studies were included in the review.

\section{Eligibility Criteria}

Irrespective of study design, studies were included which recruited participants aged 18 years or above, who were either healthy or had physical or psychological health conditions. All studies statistically examined the effect of mindfulness-based interventions, or interventions including predominantly mindfulness elements (according to a mindfulness definition that observes acceptance, compassion, and detachment (Bogosian et al. 2016; Desrosiers et al. 2013; Pinto-Gouveia et al. 2014) (Kabat-Zinn 2006) as key therapeutic concepts), on mental or physical health outcomes. Interventions using yoga, Tai chi, or other meditative practices such as transcendental meditation, which include elements of mindfulness but are considered distinct from mindfulness-based interventions, were not included in the review. MBIs that used the key therapeutic concepts defined above, such as body scan meditations or acceptance or non-judgment strategies, were included. Multicomponent interventions, which included mindfulnessbased interventions alongside other components, such as educational support, were not included as in these studies it is not possible to examine the independent effect of the mindfulness element.

Only "brief" interventions were included and these were defined as being of a duration of 30 min or less on any one occasion, totaling no more than 100 min per week, and lasting up to 4 weeks. There is no standard definition of "brief" MBIs in the literature but this definition is consistent with studies that define their intervention as brief. Also, this definition constitutes approximately half of what constitutes a standard MBSR course (both in duration of individual sessions and of the overall program), which usually is 1 hour daily spread over 8 weeks. Outcome measures included those quantifying mental or physical outcomes.

\section{Search Strategy}

Searches were conducted using Medline, Embase, PsycINFO, and CINAHL databases. Hand searches of reference lists of eligible papers, and of key authors, were also conducted. Searches had no date restrictions, were conducted up to June 2018, and were limited to English language papers. Databases were searched using a combination of the key words: "pain," "mood," "stress," "illness," "anxiety," "depression," "attention," "cognition," "emotion*," "acceptance," "mindful*," "treatment," "intervention," and "strateg*."

\section{Data Extraction}

Titles and abstracts were screened for eligibility by one reviewer $(\mathrm{AH})$, in the first instance, to identify abstracts as either highly relevant, potentially relevant, or not relevant. Full texts were then retrieved for all abstracts identified as highly or potentially relevant and read in full by two reviewers $(\mathrm{AH}$ and MU) to determine whether they were eligible. Any studies that were considered ambiguous, with regard to the inclusion criteria, were discussed, and consensus was reached for all articles included.

The following data was extracted from each eligible study report by $\mathrm{AH}$ and verified by MU, LP or JS: first author name, publication date, study location, aim and design, key sample characteristics (including age, gender, ethnicity, and health status), type of intervention, comparison, main outcome measures, and results (i.e., effects of interventions on outcomes). 
Fig. 1 PRISMA flow diagram illustrating the identification of studies

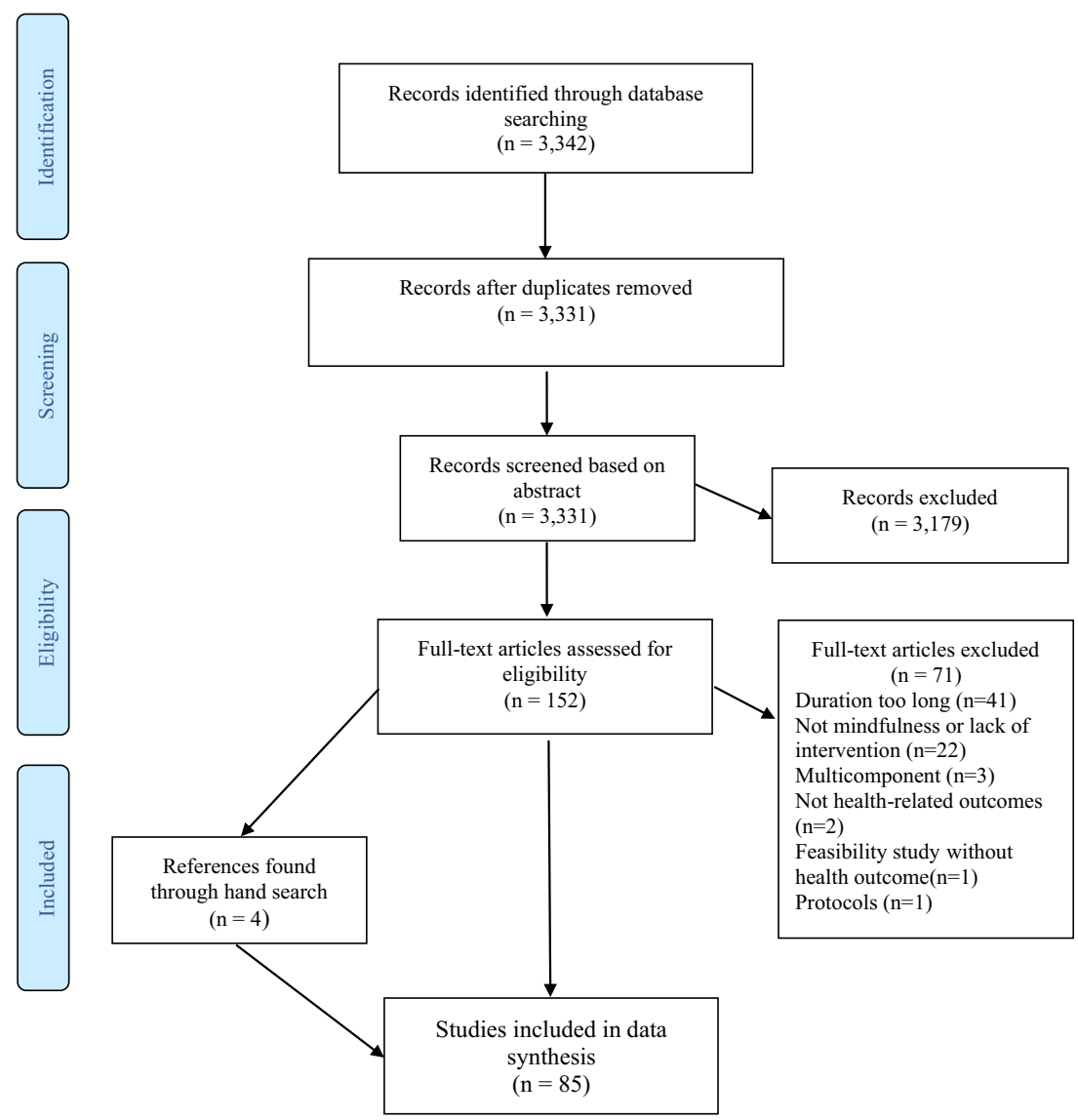

\section{Assessment of Quality}

We assessed the methodological quality of the included studies as recommended by the Cochrane Handbook for Systematic Reviews of Interventions (Higgins and Green 2008b). The GRADE (Grading of Recommendations, Assessment, Development and Evaluation) (Higgins and Green 2008a) approach was used in combination with the Cochrane risk of bias tool (Higgins et al. 2011). Grades were allocated for each study dependent on how key issues such as randomization, allocation concealment, blinding and full reporting of outcome measures were addressed. If these areas did not appear to be addressed appropriately, then a high risk of bias classification was allocated (i.e., indicating lower quality), if these areas appeared to be addressed overall, then a low risk of bias classification was allocated (i.e., indication higher quality), and if there was insufficient detail reported regarding these areas, then an unclear risk of bias was allocated.

\section{Analysis}

After inspection of included papers, meta-analysis was not considered appropriate as there were insufficient studies with the required level of homogeneity in the type of brief
BMI, outcome measures, and the timing of these measures (Higgins and Green 2008b). Consequently, the findings are summarized using a narrative approach and we have focused on high-quality studies in the results and conclusions.

\section{Results}

Of the 85 studies in the review, all studies except one (Brunyé et al. 2013) (which did not state how participants were allocated) were randomized. The sample sizes ranged from 12 to 794 participants, with a median (interquartile range $=48$ to 104.3 ) of 74 participants and a combined total of 7837 participants. Almost half of the studies ( $n=37$ ) were conducted in the USA and the remaining studies were conducted across various countries including the UK, Australia, Romania, Germany, New Zealand, and Spain.

\section{Participant Characteristics}

More than half of the studies $(n=47)$ recruited healthy university students as participants with 15 of these studies specifying meditation naïve participants (Banks et al. 2015; 
Eisenbeck et al. 2018; Feldman et al. 2010; Gamboa et al. 2017; Johnson et al. 2015; Lai et al. 2015; Lebois et al. 2015; Liu et al. 2013; Papies et al. 2012; Pepping et al. 2015; Steffen and Larson 2014; Zeidan et al. 2010a, c, 2011). Fourteen studies recruited participants who had either a diagnosed mental health disorder or were classified as having maladaptive psychological responses (Azam et al. 2015; Barnhofer et al. 2010; Campbell-Sills et al. 2006; Gkika and Wells 2015; Keng and Tan 2018; Kuehner et al. 2009; Lee and Orsillo 2014; McClintock and Anderson 2015; Nasser and Przeworski 2017; Singer and Dobson 2007). The average age for $77 \%$ of the studies was under 30 years, $86 \%$ of all studies included males and females, and of the studies reporting ethnicity $(n=36)$, most $(n=25)$ consisted of over $60 \%$ Caucasian participants.

\section{Study Characteristics}

A summary of the study characteristics is presented in Table 1, which is reported in Electronic Supplementary Material 1.

\section{Intervention Characteristics}

\section{Type of Mindfulness}

The majority of MBIs included mindfulness breathing exercises $(n=26)$ or general mindfulness instructions, inductions, or strategies $(n=25)$ (see Table 1, supplementary material 1). The mindfulness breathing tended to be purely meditative sessions where the breath was focused upon and some of which were mixed with educational, general induction or body scan techniques $(n=9)$ and the general mindfulness instructions, inductions, or strategies usually included an introduction to key mindfulness concepts, such as present moment focus and awareness, along with brief meditative exercises. The next most common type of mindfulness were those involving the use of mindfulness-acceptance practice $(n=14)$ (Ainsworth et al. 2015; Alberts et al. 2013; Atkinson and Wade 2012; Campbell-Sills et al. 2006; Dixon-Gordon et al. 2017; Hofmann et al. 2009; Singer and Dobson 2007; Szasz et al. 2016; 2011, 2012; Troy et al. 2018; Wade et al. 2009; Westbrook et al. 2013; Wolgast et al. 2011). The remaining studies included MBIs with a range of focuses such as mindfulness eating, open monitoring or cognitive diffusion training, and focused attention training sometimes combined $(n=$ 14) (Ainsworth et al. 2015; Bowen and Marlatt 2009; Díaz et al. 2014; Eisenbeck et al. 2018; Gkika and Wells 2015; Herwig et al. 2010; Lebois et al. 2015; Marek et al. 2013; Papies et al. 2012, 2015; Scherpiet et al. 2015; Schofield et al. 2015; Tincher et al. 2016) and six studies used a mindfulness body scan alone (Bonamo et al. 2015; Cropley et al. 2007; Hamilton et al. 2013; Sharpe et al. 2013; Ussher et al. 2009; Ussher et al. 2012).

\section{Mode of administration}

The most common method of intervention delivery was by audio, with more than half of the studies using brief audio recordings $(n=49)$. After this, the most common mode of administration was verbal instructions $(n=14)$ by instructors or experimenters (Cullen et al. 2007; Gamboa et al. 2017; Gkika and Wells 2015; Green and Black 2017; Jenkins and Tapper 2014; Lai et al. 2015; Lee and Orsillo 2014; Pepping et al. 2015; Rogojanski et al. 2011; Schofield et al. 2015; Swain and Trevena 2014; Westbrook et al. 2013; Zeidan et al. 2010b, c). A further 13 studies used interventions used written instructions (Baquedano et al. 2017; Herwig et al. 2010; Hofmann et al. 2009; A. Lutz et al. 2013; Metcalfe et al. n.d.; Scherpiet et al. 2015; Szasz et al. 2016, 2012; Tincher et al. 2016; Troy et al. 2018; Wilson et al. 2014; Wolgast et al. 2011; Zeidan et al. 2011) and the remaining $(n=10)$ used a mix of modes (e.g., verbal and video) (Atkinson and Wade 2012; Bowen and Marlatt 2009; Díaz et al. 2014; Huffziger and Kuehner 2009; Kuehner et al. 2009; Lebois et al. 2015; Papies et al. 2012, 2015; Wade et al. 2009; Westenberg et al. 2018).

\section{Length and frequency}

The majority of interventions were given as a single session $(n=74)$, mostly in laboratory settings. The interventions in this group ranged from less than 5 to $25 \mathrm{~min}$ in length, with an average length of $15 \mathrm{~min}$. Of the remaining 11 interventions, ten were given two to four times in under 1 week, and ranged in length from 10 to $25 \mathrm{~min}$, with the average being 20 min per session (Banks et al. 2015; Creswell et al. 2014; Cropley et al. 2007; Gkika and Wells 2015; Lebois et al. 2015; Nasser and Przeworski 2017; Ussher et al. 2009, 2012; Wenk-Sormaz 2005; Zeidan et al. 2015; Zeidan et al. 2010a). Regardless of session duration or frequency, all interventions, except one (Banks et al. 2015), were conducted within a week. This other intervention was $15 \mathrm{~min}$ in length and was daily over 7 to 10 days depending on how often the participant wanted to use it (Banks et al. 2015). The total length of time for all interventions combined was just over $24 \mathrm{~h}$ and the median length was $10 \mathrm{~min}$.

\section{Control/Comparison Conditions}

There were a wide variety of comparisons and controls used, with a total of 140 conditions used across the 85 studies. The most common study design $(n=44)$ employed more than two conditions, aside from the main MBI. Two of these studies (May et al. 2010; Wade et al. 2009) had five conditions (including the intervention condition), four studies (Broderick 2005; Papies et al. 
2015; Singer and Dobson 2007; Zeidan et al. 2015) had four conditions in total, and the remaining studies $(n=$ 40) had three conditions. After this, the most common design $(n=34)$ employed the use of one closely matched comparison group. These groups had a control or comparison that was usually matched in length and delivery (e.g., audio of same length as intervention but content not mindful in nature, such as a reading from a historical text). Finally, the least common type of control or comparison $(n=5)$ employed was a condition where there was no instruction, strategy, or activity given to fill the time (Atkinson and Wade 2012; Bowen and Marlatt 2009; Lutz et al. 2014; McHugh and Wood 2013; Westbrook et al. 2013).

All controls and comparisons were time matched except in one study where a 20 min body scan was compared with a 45 min body scan (Bonamo et al. 2015). A quarter of the studies $(n=22)$ included a comparison/ control group that could be considered passive where participants were not given a task or strategy but most groups tended towards more active content. The most common of these conditions overall was audio readings usually from a book $(n=12)$, where the voice and dictation were closely matched (Cropley et al. 2007; Eisenbeck et al. 2018; Fisher et al. 2016; Grant et al. 2013; Johnson et al. 2015; Luberto and McLeish 2018; Pepping et al. 2015; PerkinsPorras et al. 2018; Ussher et al. 2009, 2012; Zeidan et al. $2015 ; 2010 \mathrm{c})$. After that, conditions consisting of a selection of distraction $(n=10)$, suppression $(n=8)$, or relaxation $(n=8)$ exercises were most often employed, sometimes in combination (Banks et al. 2015; Broderick 2005; Kuehner et al. 2009; Singer and Dobson 2007; Szasz et al. 2011, 2012; Wade et al. 2009; Wilson et al. 2014; Zeidan et al. 2010a). The remaining studies employed a combination of unique conditions including hypnosis (Swain and Trevena 2014), guided imagery (Hamilton et al. 2013; May et al. 2010), and progressive muscle relaxation (Feldman et al. 2010; Green and Black 2017; Lancaster et al. 2016; Sharpe et al. 2013).

\section{Outcomes}

\section{Mindfulness Measures}

Mindfulness was assessed across 47 studies, using nine differentmeasures: the Toronto Mindfulness Scale $(n=11)$, Five Facet Mindfulness Questionnaire $(n=11)$, Mindful Attention Awareness Scale $(n=10)$, Freiburg Mindfulness Inventory $(n=5)$, Philadelphia Mindfulness Scale $(n=4)$, the State Mindfulness Scale $(n=2)$, Meditation Breath Attention Scores $(n=1)$, Kentucky Inventory of Mindfulness Skills $(n=1)$, and Cognitive Affective Mindfulness Scale $(n=1)$. One study used a single-item measure for mindfulness.

\section{Psychological Measures}

One hundred and nine different psychological measures were used across 70 studies. Pain-related measures were the most common with 18 instances of pain measures (most commonly general pain and pain tolerance ratings) and only one study (Ussher et al. 2012) used a standardized pain measure which was the Brief Pain Inventory (Cleeland and Ryan 1994). Moodrelated measures were the next most frequently employed, with 15 different measures used in 48 instances — over half $(n=25)$ of these studies employed the Positive and Negative Affect Schedule (Crawford et al. 2001). Following this, the most common were anxiety measures, which covered nine different measures in 30 instances, almost half $(n=13)$ of which were measures of state anxiety (most commonly using the State-Trait Anxiety Inventory) (Spielberger et al. 1970). Fifteen studies measured depression, using seven measures a total of 16 times and a couple of studies used a combination anxiety and depression measure, such as the Hospital Anxiety and Depression Scale. The remaining psychological measures used were varied $(n=72)$ and difficult to group or categorize; these measures included ratings of perceived social functioning, distress, food craving, interpersonal dependency, body satisfaction, and beliefs about rumination and acceptance.

\section{Cognitive Measures}

Across 26 studies, 39 different cognitive measures were employed to investigate processes such as memory, attention, unconscious and conscious thought, and decision-making. Only seven measures were used more than once and examples of these measures included variations of the Stroop test, the Attention Control Scale, the Paced Auditory Serial Addition Task, the Symbol Digit Modalities Test, and the Wechsler Adult Intelligence Scale.

\section{Physiological Measures}

There were 40 instances of physiological measures, predominantly measuring heart rate, blood pressure, brain activity, and cortisol levels. Heart rate and blood pressure were common measures in studies that included a stressor task or emotional induction; responses to these tasks or inductions were assessed with a variety of methods including electrocardiogram recordings, electroencephalogram output, antisaccadic eye-movement measures, skin conductance, facial electromyography, and expired breath carbon monoxide level.

\section{Behavioral Measures}

There were 30 instances of behavioral measures being used; the Fagerström Test of Nicotine Dependence (Heatherton et al. 1991) was the most common, being used six times 
(Bowen and Marlatt 2009; Cropley et al. 2007; Luberto and McLeish 2018, b; Rogojanski et al. 2011; Szasz et al. 2012; Ussher et al. 2009; Westbrook et al. 2013). Other examples of behavioral measures were the approach-avoidance task, food and eating behaviors, including calorie intake, and willingness to view aversive picture slides.

\section{Positive Findings}

Seventy-nine (93\%) reported significant positive effects of the MBI, although 52 of these studies included mixed significant and non-significant findings. Of the 79 studies with one or more significant positive findings, 19 focused on very specific populations; these most often concerned participants with mental health issues $(n=13)$, six of which had borderline personality disorder or were maladaptive perfectionists or classified as having high trait interpersonal dependency (Azam et al. 2015; Dixon-Gordon et al. 2017; Keng and Tan 2018; McClintock and Anderson 2015; Metcalfe et al. n.d.; Scherpiet et al. 2015), four were anxiety-related (CampbellSills et al. 2006; Gkika and Wells 2015; Lee and Orsillo 2014; Nasser and Przeworski 2017), and three were depressive (Barnhofer et al. 2010; Huffziger and Kuehner 2009; Singer and Dobson 2007).

The next most common population targeted were smokers $(n=6)$ (Bowen and Marlatt 2009; Cropley et al. 2007; Szasz et al. 2012; Ussher et al. 2009; Westbrook et al. 2013), usually with consumption of ten or more cigarettes per day required for eligibility. Lastly, six studies examined populations with physical illness or pain. One study found improvements on a selectivity task within a traumatic brain injury population (McHugh and Wood 2013), another found lowered blood pressure with hypertensive African-American males with chronic kidney disease (Park et al. 2014), another found improved body satisfaction compared with healthy controls with participants with eating disorders (Marek et al. 2013), and finally, three studies found patients with pain (i.e., one chronic, one acute, and one in-patient unmanaged) had reduced pain-related distress, pain interference (Ussher et al. 2012), and intensity (Garland et al. 2017; Westenberg et al. 2018).

Other studies, using more general (non-clinical) populations, found significant improvements and positive changes on a variety of cognitive measures $(n=25)$, including tasks measuring memory and attentional processes. A further 13 studies found improvements with psychological processes such as stress and negative affect, as well as overall emotional regulation. Four studies reported significant positive findings with experimental pain (Liu et al. 2013; Swain and Trevena 2014; Zeidan et al. 2015, 2010a) and one study reported improvement with cardiovascular reactivity (Steffen and Larson 2014). A further seven studies employed a combination of different types of outcome measures (e.g., psychological and behavioral or physical) with significant results, including decreased negative affect and improved cortisol responses during experimental mood induction (Kuehner et al. 2009). Finally, four studies with healthy populations found significant improvements with eating or smoking behaviors (Fisher et al. 2016; Jenkins and Tapper 2013; Papies et al. 2015; Szasz et al. 2012).

\section{Mixed and Negative Findings}

Only six studies did not report any significant findings for a MBI (Alberts et al. 2013; Gamboa et al. 2017; Grant et al. 2013; Perkins-Porras et al. 2018; Sharpe et al. 2013; Szasz et al. 2012); these studies investigated the effects on experimental pain tasks, food cravings, smoking cravings, COPD symptom distress, and cardiovascular reactivity and recovery. However, all six studies used a one-off mindfulness session, and a common conclusion among the authors was that longer or more frequent mindfulness sessions may be more impactful.

A final study classified as having negative or mixed findings investigated emotional regulation strategies during stressinducing tasks (Wilson et al. 2014). This study is distinct in that the mindfulness condition did not have a significant effect but the study also included an acceptance condition (considered a key component of mindfulness and, as such, studies with acceptance interventions were included in the review), which did show a significant effect compared with the control group.

\section{Quality of Studies}

Of the 85 studies, 83 were classified as having an "unclear" risk of bias; this was most commonly due to lack of reporting of allocation concealment, blinding, and lack analysis of large groups or drop-outs who did not finish the study.

Only three studies were assessed as having low risk of bias and therefore higher quality. Two of these studies reported being able to blind both participants and researchers conducting outcome assessments to the treatment assignment (Creswell et al. 2014; Liu et al. 2012) and another blinded the experimenters only (Creswell et al., 2014).

\section{Discussion}

This review considered the effects of brief MBIs on healthrelated outcomes. Eighty-five studies were eligible and covered a broad range of outcomes, with an equally varied range of measures. Most commonly, studies recruited healthy young adults who were asked to listen to an audio intervention (typically $10-15 \mathrm{~min}$ in length) on a single occasion. Almost half of the interventions consisted of general mindfulness instructions or breathing exercises and over $90 \%$ of the studies 
reported a positive significant effect of brief MBIs on at least one health-related outcome.

Based solely on the detail included (and disregarding the lack of reporting overall for some key areas of risk of bias), 71 of the studies included were methodologically adequate to robust. A broad selection of standardized and validated instruments was used to assess outcomes, making it possible to examine many different ways a brief MBI can impact health across the literature. With more than two-thirds of the studies having reasonable sample sizes (i.e., $\geq 50$ ) and all but one study (Brunyé et al. 2013) being an RCT, the combined results can be interpreted as being fairly robust. Despite this, evidence must be interpreted cautiously as all but three studies (Garland et al. 2017; Perkins-Porras et al. 2018; Westenberg et al. 2018) were largely conducted within a laboratory. Part of the rationale for this review was to assess the impact on health-related outcomes due to the large growth in the use of brief MBIs that have been promoted as positively impacting health in everyday life. The fact that most outcomes were observed only in a laboratory setting means that generalizability is an issue and illustrates the urgent need for future research to focus on examining MBIs in participants' own environment. Although engagement is hard to capture outside the laboratory, realtime measurement is becoming more feasible due to the same advancements in technology that encourage widespread use of many brief MBIs (i.e., apps) and the use of self-monitoring wearable devices (i.e., smart watches, Fitbit) for health has grown globally. Despite limitations, studies in this review offer a foundation for future research and key studies are discussed below according to outcome.

\section{General Psychological Outcomes}

The evidence for brief MBIs improving psychological outcomes, especially for anxiety and depression, was convincing. This group, which covered a range of general psychological outcomes, was the most common category. Almost half of the studies with psychological outcome measures reported significant positive results for all outcomes providing some evidence that a brief MBI (i.e., of five to 20 min duration), in a single session, can positively impact negative mood and different types of anxiety, or related factors such as rumination in both healthy or clinical populations. These MBIs were mostly mindfulness audios, but mindfulness cue cards and instructions were also found to be effective.

There were also studies with psychological outcomes that reported mixed results but perhaps the findings were contextrelated. For example, in a mood induction study (CampbellSills et al. 2006), a 5-min MBI was found to lower distress levels and HR compared with a thought suppression control condition; however, the magnitude of the effects may have been influenced by the control condition being "aggravating" rather than neutral. In another study, with an experimental stressor (Hofmann et al. 2009), both mindfulness and reappraisal instructions (i.e., comparison condition) reduced HR compared with thought suppression, but interestingly only the reappraisal condition reduced self-reported anxiety. The mindfulness technique used was an acceptance strategy, a strategy found to be less effective in some circumstances (Alberts et al. 2013; Szasz et al. 2012). In the instances where the comparison groups were found to have significant effects alongside the MBI group, the authors often noted that more practice (i.e. increased duration and frequency) would likely lead to the advantage of the MBIs becoming more distinguishable from other therapeutic comparisons. Although this review presents studies which suggest psychological outcomes may be a promising focus for MBIs, the need for standardized comparison groups and consistent pairing of specific types of MBIs with specific psychological outcomes is warranted.

\section{Emotional Regulation Outcomes}

The next largest area of impact as defined by the outcome was the group related to emotion or emotional regulation. Some studies showed benefits illustrating that brief MBIs are capable of reducing negative affect and body dissatisfaction (Atkinson and Wade 2012) as well as supporting emotional regulation in a stress experiment with distressed mood (Azam et al. 2015). Other findings in this group were mixed but overall supported brief MBIs having a beneficial effect on a range of negative emotions including anger, sadness, and maladaptive distress responses. The inclusion of unique placebo controls as well as active controls was an advantage in this group of studies. Some controls included sham meditation (i.e., participants told that they were meditating by sitting quietly and breathing deeply) (Johnson et al. 2015; Zeidan et al. 2010b), alongside more "active" control conditions, such as appraisal strategies (Arch and Craske 2006; Herwig et al. 2010; Papies et al. 2012; Scherpiet et al. 2015; Szasz et al. 2016, 2011; Wolgast et al. 2011), which provided relevant comparisons and strengthened the findings overall for emotion regulation outcomes.

\section{Cognitive Outcomes}

Among studies with a cognitive focus, significant effects were found for MBIs improving a variety of cognitive functions including attention (Bonamo et al. 2015; Lai et al. 2015; Schofield et al. 2015; Zeidan et al. 2010c), memory (Bonamo et al. 2015), and even temporal brain injury symptoms (McHugh and Wood 2013). One study was revealing in that it compared a $20 \mathrm{~min}$ and $45 \mathrm{~min}$ MBI (Bonamo et al. 2015) and found that both interventions enhanced word recall in comparison with a control but when symptoms of depression, anxiety, and attention were controlled for, state levels of mindfulness were only significantly increased after the shorter 
MBI. The authors suggested that perhaps the longer session left some participants sluggish and/or irritated, especially for those not familiar with mindfulness practice. This illustrates the need for further investigation of dose effects to determine if there are thresholds for positive effects on different outcome measures. Additionally, it would be beneficial to know if there are adverse effects (e.g., "feeling sleepy") if certain MBIs of longer lengths are introduced too early when learning mindfulness. Mindfulness meditation is often referred to as a practice, which suggests sessions might be best if introduced in small doses and then eventually built up over time.

\section{Experimental Stress}

There is a large amount of literature supporting the link between mindfulness and positive stress management (Goyal et al. 2014). Experimental stress studies in this review generally reflected these results, despite the brevity of the interventions. Use of MBIs either before or after a stressor was found to be beneficial for improving various stress-related outcomes whether self-reported stress or stress measured using fMRI. However, despite distinct outcomes, the studies were heterogeneous in nature (e.g., timing of intervention, population, and measures), which makes it difficult to draw firm conclusions. As an example, two studies examined MBIs on more than one occasion (i.e., daily for 1 week or three times within 1 week) (Banks et al. 2015; Creswell et al. 2014) which was unique among the studies in this review and another two studies recruited only females (Díaz et al. 2014; Feldman et al. 2010) which limits generalizability.

\section{Other Outcomes}

The remaining studies worth noting covered outcomes related to eating, pain, and smoking. For studies on eating, it was difficult to judge the benefits due to the great variety of outcomes (e.g., cravings, food consumption, and food choices), and lengths, and format of the interventions (i.e., ranging from instructions to $20 \mathrm{~min}$ exercises). However, all resulted in an improvement in at least one outcome with the exception of a study where the control group was allowed to eat (while the MBI group was not); not surprisingly, the control group reported less food cravings than the MBI group (Alberts et al. 2013). This study also demonstrated the phenomena (mentioned previously) where the immediate effects of an MBI were not perceived as positive. Instead, the brief MBI used in this instance (i.e., acceptance strategy) encouraged heightened present moment awareness and resulted in short-term counter-productive effects as the present moment was an unpleasant one, again highlighting the need for future research to look at dose effects. Similarly, "pain" studies brought attention to another research issue. To examine MBI impact on pain, only one study (Ussher et al. 2012) recruited a chronic pain population and only two studies recruited patients in a hospital setting with pain (Garland et al. 2017; Westenberg et al. 2018). As all three of these studies involving real pain patients had positive results, more research recruiting a more relevant population may be beneficial considering the current demand for non-pharmaceutical treatments that are nonburdensome.

Finally, the smoking-related studies also provided an example of an overabundance of variation. Audio body scans tested both in clinic (Cropley et al. 2007) and in the participant's own environment (Ussher et al. 2009) were investigated along with unique interventions such as mindfulness "urgesurfing" techniques (e.g., imagining craving as a wave that peaks and then naturally subsides) (Bowen and Marlatt 2009; Szasz et al. 2011). Procedural differences such as prior smoking abstinence timings (e.g., from 1 to $12 \mathrm{~h}$ ) along with a range of intervention types (e.g., instructions through to practiced "urge-surfing" techniques) resulted in what appears to be successful results for MBIs with smoking but once again it is difficult to draw firm conclusions. Outcomes in this group ranged from the amount of cravings reported during a session to smoking behavior (i.e., how many cigarettes smoked) after 1 week. However, there was one unsuccessful study (Szasz et al. 2012) which used a mindfulness-acceptance strategy to regulate cravings, mood, and attention compared with a reappraisal strategy. Again, perhaps the use of certain MBIs (i.e., acceptance strategies), which encourages heightened awareness regardless if something is unpleasant (e.g., coping with an immediate craving), is inadequate when looking for immediate effects.

\section{Strengths and Limitations of the Review}

Strengths of this review include the methodological advantages of a published protocol, a quality assessment in relation to risk of bias, the inclusion of a large number of studies, which were almost all RCTs, and consideration of a broad range of health outcomes. There are also limitations. Many of the studies used a narrow population (e.g., healthy university students) and were conducted in a laboratory setting. Also, deciding upon a finite definition of a brief MBI was potentially biasing; an arbitrary cut-off point with regard to duration and length meant that some studies that were very nearly eligible had to be excluded, although these studies were also noted in the review. Overall, it is difficult to summarize the overall evidence for brief MBIs due to the vast array of outcomes and heterogeneity in methods. Instead, the conclusions are specific to the factors of MBI, population recruited, outcome, and experimental context. This is in strong contrast with the literature covering full-length traditional MBIs, where there is clear evidence for benefits irrespective of differences in these factors. 


\section{Future Research}

The evidence indicates that there are many benefits for brief MBIs, even when administered over just one session and for as little as $5 \mathrm{~min}$. However, the lack of long-term follow-up and analysis of dose effects may limit the evidence for the clinical application of brief MBIs. Furthermore, when self-management skills and coping abilities are in high demand within healthcare, future research should investigate popular and easily accessible interventions in real time with relevant populations. Finally, the standardization of interventions and outcomes will also be essential to building a stronger evidence base.

Author Contributions AH designed and executed the review, analyzed data, and wrote the paper. JS assisted with analyzing the data and with the writing of the paper. LP assisted with analyzing the data and writing the paper. MU collaborated on the design, data analysis, and writing of the paper.

Funding Information The study was funded by St George's, University of London.

\section{Compliance with Ethical Standards}

Ethical Approval This article does not contain any studies with human participants or animals performed by any of the authors.

Conflict of Interest The authors declare that they have no conflict of interest.

Open Access This article is distributed under the terms of the Creative Commons Attribution 4.0 International License (http:// creativecommons.org/licenses/by/4.0/), which permits unrestricted use, distribution, and reproduction in any medium, provided you give appropriate credit to the original author(s) and the source, provide a link to the Creative Commons license, and indicate if changes were made.

\section{References}

Ainsworth, B., Marshall, J. E., Meron, D., Baldwin, D. S., Chadwick, P., Munafò, M. R., \& Garner, M. (2015). Evaluating psychological interventions in a novel experimental human model of anxiety. Journal of Psychiatric Research, 63, 117-122. https://doi.org/10. 1016/j.jpsychires.2015.02.001.

Alberts, H. J. E. M., Thewissen, R., \& Middelweerd, M. (2013). Accepting or suppressing the desire to eat: Investigating the short-term effects of acceptance-based craving regulation. Eating Behaviors, 14(3), 405409. https://doi.org/10.1016/j.eatbeh.2013.06.008.

Arch, J. J., \& Craske, M. G. (2006). Mechanisms of mindfulness: Emotion regulation following a focused breathing induction. Behaviour Research and Therapy, 44(12), 1849-1858. https://doi. org/10.1016/j.brat.2005.12.007.

Atkinson, M. J., \& Wade, T. D. (2012). Impact of metacognitive acceptance on body dissatisfaction and negative affect: engagement and efficacy. Journal of Consulting and Clinical Psychology, 80(3), 416-425. https://doi.org/10.1037/a0028263.

Azam, M. A., Katz, J., Fashler, S. R., Changoor, T., Azargive, S., \& Ritvo, P. (2015). Heart rate variability is enhanced in controls but not maladaptive perfectionists during brief mindfulness meditation following stress-induction: a stratified-randomized trial.
International Journal of Psychophysiology, 98(1), 27-34. https:// doi.org/10.1016/j.ijpsycho.2015.06.005.

Banks, J. B., Welhaf, M. S., \& Srour, A. (2015). The protective effects of brief mindfulness meditation training. Consciousness and Cognition, 33, 277-285. https://doi.org/10.1016/j.concog.2015.01. 016.

Baquedano, C., Vergara, R., Lopez, V., Fabar, C., Cosmelli, D., \& Lutz, A. (2017). Compared to self-immersion, mindful attention reduces salivation and automatic food bias. Scientific Reports, 7(1), 13839. https://doi.org/10.1038/s41598-017-13662-z.

Barnhofer, T., Chittka, T., Nightingale, H., Visser, C., \& Crane, C. (2010). State effects of two forms of meditation on prefrontal EEG asymmetry in previously depressed individuals. Mindfulness, $1(1), 21-$ 27. https://doi.org/10.1007/s12671-010-0004-7.

Bogosian, A., Hughes, A., Norton, S., Silber, E., \& Moss-Morris, R. (2016). Potential treatment mechanisms in a mindfulness-based intervention for people with progressive multiple sclerosis. British Journal of Health Psychology, 21(4), 859-880. https://doi.org/10. 1111/bjhp.12201.

Bonamo, K. K., Legerski, J.-P., \& Thomas, K. B. (2015). The influence of a brief mindfulness exercise on encoding of novel words in female college students. Mindfulness, 6(3), 535-544. https://doi.org/10. 1007/s12671-014-0285-3.

Bowen, S., \& Marlatt, A. (2009). Surfing the urge: brief mindfulnessbased intervention for college student smokers. Psychology of Addictive Behaviors, 23(4), 666-671. https://doi.org/10.1037/ a0017127.

Broderick, P. C. (2005). Mindfulness and coping with dysphoric mood: contrasts with rumination and distraction. Cognitive Therapy and Research, 29(5), 501-510. https://doi.org/10.1007/s10608-0053888-0.

Brunyé, T. T., Mahoney, C. R., Giles, G. E., Rapp, D. N., Taylor, H. A., \& Kanarek, R. B. (2013). Learning to relax: evaluating four brief interventions for overcoming the negative emotions accompanying math anxiety. Learning and Individual Differences, 27, 1-7. https://doi.org/10.1016/j.lindif.2013.06.008.

Campbell-Sills, L., Barlow, D. H., Brown, T. A., \& Hofmann, S. G. (2006). Effects of suppression and acceptance on emotional responses of individuals with anxiety and mood disorders. Behaviour Research and Therapy, 44(9), 1251-1263. https://doi. org/10.1016/j.brat.2005.10.001.

Cavanagh, K., Strauss, C., Forder, L., \& Jones, F. (2014). Can mindfulness and acceptance be learnt by self-help? A systematic review and meta-analysis of mindfulness and acceptance-based self-help interventions. Clinical Psychology Review, 34(2), 118-129. https://doi. org/10.1016/j.cpr.2014.01.001.

Chen, P., Jindani, F., Perry, J., \& Turner, N. L. (2014). Mindfulness and problem gambling treatment. Asian Journal of Gambling Issues and Public Health, 4(1), 2. https://doi.org/10.1186/2195-3007-4-2.

Cherkin, D. C., Sherman, K. J., Balderson, B. H., Cook, A. J., Anderson, M. L., Hawkes, R. J., et al. (2016). Effect of mindfulness-based stress reduction vs cognitive behavioral therapy or usual care on back pain and functional limitations in adults with chronic low back pain. JAMA, 315(12), 1240. https://doi.org/10.1001/jama.2016. 2323.

Cleeland, C. S., \& Ryan, K. M. (1994). Pain assessment: global use of the brief pain inventory. Annals of the Academy of Medicine, Singapore, 23(2), 129-138.

Craigie, M., Slatyer, S., Hegney, D., Osseiran-Moisson, R., Gentry, E., Davis, S., et al. (2016). A pilot evaluation of a mindful self-care and resiliency (MSCR) intervention for nurses. Mindfulness, 7(3), 764 774. https://doi.org/10.1007/s12671-016-0516-x.

Crane, R. S., \& Kuyken, W. (2013). The implementation of mindfulnessbased cognitive therapy: learning from the UK health service experience. Mindfulness, 4(3), 246-254. https://doi.org/10.1007/s12671012-0121-6. 
Crawford, J. R., Henry, J. D., Crombie, C., \& Taylor, E. P. (2001). Normative data for the HADS from a large non-clinical sample. British Journal of Clinical Psychology, 40(4), 429-434. https://doi. org/10.1348/014466501163904.

Creswell, J. D., Pacilio, L. E., Lindsay, E. K., \& Brown, K. W. (2014). Brief mindfulness meditation training alters psychological and neuroendocrine responses to social evaluative stress. Psychoneuroendocrinology, 44, 1-12. https://doi.org/10.1016/j.psyneuen.2014.02.007.

Cropley, M., Ussher, M., \& Charitou, E. (2007). Acute effects of a guided relaxation routine (body scan) on tobacco withdrawal symptoms and cravings in abstinent smokers. Addiction, 102(6), 989-993. https:// doi.org/10.1111/j.1360-0443.2007.01832.x .

Cullen, D. M., Boyle, J. J. W., Silbert, P. L., Singer, B. J., \& Singer, K. P. (2007). Botulinum toxin injection to facilitate rehabilitation of muscle imbalance syndromes in sports medicine. Disability and Rehabilitation, 29(23), 1832-1839. https://doi.org/10.1080/ 09638280701568627.

Davis, R., Campbell, R., Hildon, Z., Hobbs, L., \& Michie, S. (2015). Theories of behaviour and behaviour change across the social and behavioural sciences: a scoping review. Health Psychology Review, 9(3), 323-344. https://doi.org/10.1080/17437199.2014.941722.

Desrosiers, A., Klemanski, D. H., \& Nolen-Hoeksema, S. (2013). Mapping mindfulness facets onto dimensions of anxiety and depression. Behavior Therapy, 44(3), 373-384. https://doi.org/10.1016/j. beth.2013.02.001.

Díaz, N. S. R., Jiménez, Ó., \& Lopes, P. N. (2014). The role of mindfulness in coping with recollections of acute stressors: a laboratory study. Psicothema, 26(4), 505-510. https://doi.org/10.7334/ psicothema2014.71.

Dixon-Gordon, K. L., Turner, B. J., Zachary Rosenthal, M., \& Chapman, A. L. (2017). Emotion regulation in borderline personality disorder: an experimental investigation of the effects of instructed acceptance and suppression. Behavior Therapy, 48(6), 750-764. https://doi.org/ 10.1016/j.beth.2017.03.001

Eisenbeck, N., Luciano, C., \& Valdivia-Salas, S. (2018). Effects of a focused breathing mindfulness exercise on attention, memory, and mood: the importance of task characteristics. Behaviour Change, 35(1), 54-70. https://doi.org/10.1017/bec.2018.9.

Evans, S. (2016). Mindfulness-based cognitive therapy for generalized anxiety disorder. In Mindfulness-based cognitive therapy (pp. 145154). Cham: Springer International Publishing. https://doi.org/10. 1007/978-3-319-29866-5 13

Feldman, G., Greeson, J., \& Senville, J. (2010). Differential effects of mindful breathing, progressive muscle relaxation, and lovingkindness meditation on decentering and negative reactions to repetitive thoughts. Behaviour Research and Therapy, 48(10), 10021011. https://doi.org/10.1016/j.brat.2010.06.006.

Fisher, N., Lattimore, P., \& Malinowski, P. (2016). Attention with a mindful attitude attenuates subjective appetitive reactions and food intake following food-cue exposure. Appetite, 99, 10-16. https://doi. org/10.1016/j.appet.2015.12.009.

Gamboa, O. L., Garcia-Campayo, J., Müller, T., \& von Wegner, F. (2017). Suppress to forget: The effect of a mindfulness-based strategy during an emotional item-directed forgetting paradigm. Frontiers in Psychology, 8(432). https://doi.org/10.3389/fpsyg.2017.00432.

Garland, E. L., Baker, A. K., Larsen, P., Riquino, M. R., Priddy, S. E., Thomas, E., et al. (2017). Randomized controlled trial of brief mindfulness training and hypnotic suggestion for acute pain relief in the hospital setting. Journal of General Internal Medicine, 32(10), 1106-1113. https://doi.org/10.1007/s11606-017-4116-9.

Gkika, S., \& Wells, A. (2015). How to deal with negative thoughts? A preliminary comparison of detached mindfulness and thought evaluation in socially anxious individuals. Cognitive Therapy and Research, 39(1), 23-30. https://doi.org/10.1007/s10608-0149637-5
Gotink, R. A., Chu, P., Busschbach, J. J. V., Benson, H., Fricchione, G. L., \& Hunink, M. G. M. (2015). Standardised mindfulness-based interventions in healthcare: an overview of systematic reviews and meta-analyses of RCTs. PLoS One, 10(4), e0124344. https://doi.org/ 10.1371/journal.pone.0124344.

Goyal, M., Singh, S., Sibinga, E. M. S., Gould, N. F., Rowland-Seymour, A., Sharma, R., et al. (2014). Meditation programs for psychological stress and well-being: a systematic review and meta-analysis. JAMA Internal Medicine, 174(3), 357-368. https://doi.org/10.1001/ jamainternmed.2013.13018.

Grant, C., Persons, E., Hwang, V., Danoff-burg, S., \& Al, G. E. T. (2013). Cardiovascular reactivity to and recovery from stressful tasks following a mindfulness analog in college students with a family history of hypertension. Journal of Alternative and Complementary Medicine, 19(4), 341-346. https://doi.org/10.1089/acm.2011.0880.

Green, J. P., \& Black, K. N. (2017). Meditation-focused attention with the MBAS and solving anagrams. Psychology of Consciousness: Theory Research, and Practice, 4(4), 348-366. https://doi.org/10. 1037/cns0000113.

Hamilton, J., Fawson, S., May, J., Andrade, J., \& Kavanagh, D. J. (2013). Brief guided imagery and body scanning interventions reduce food cravings. Appetite, 71, 158-162. https://doi.org/10.1016/j.appet. 2013.08.005.

Heatherton, T. F., Kozlowski, L. T., Frecker, R. C., \& Fagerström, K. O. (1991). The Fagerström test for nicotine dependence: a revision of the Fagerström tolerance questionnaire. British Journal of Addiction, 86(9), 1119-1127.

Herwig, U., Kaffenberger, T., Jäncke, L., \& Brühl, A. B. (2010). Selfrelated awareness and emotion regulation. NeuroImage, 50(2), 734 741. https://doi.org/10.1016/j.neuroimage.2009.12.089.

Higgins, J. P., \& Green, S. (2008a). 12.2.1 The GRADE approach. In Cochrane handbook for systematic reviews of interventions Version 5.1.0 [updated March 2011] (pp. 1-649). Chichester: Wiley.

Higgins, J. P., \& Green, S. (2008b). Cochrane handbook for systematic reviews of interventions Version 5.1.0 [updated March 2011]. In J. P. Higgins \& S. Green (Eds.), Cochrane handbook for systematic reviews of interventions. Chichester, Wiley. https://oi.org/10.1002/ 9780470712184

Higgins, J. P. T., Altman, D. G., Gøtzsche, P. C., Jüni, P., Moher, D., Oxman, A. D., ... Sterne, J. A. C. (2011). The Cochrane Collaboration's tool for assessing risk of bias in randomised trials. $B M J, 343$.

Hill, J. O., Wyatt, H. R., Reed, G. W., \& Peters, J. C. (2003). Obesity and the environment: where do we go from here? Science (New York, N.Y.), 299(5608), 853-855. https://doi.org/10.1126/science. 1079857.

Hilton, L., Hempel, S., Ewing, B. A., Apaydin, E., Xenakis, L., Newberry, S., et al. (2017). Mindfulness meditation for chronic pain: systematic review and meta-analysis. Annals of Behavioral Medicine, 51(2), 199-213. https://doi.org/10.1007/s12160-0169844-2.

Hofmann, S. G., Heering, S., Sawyer, A. T., \& Asnaani, A. (2009). How to handle anxiety: the effects of reappraisal, acceptance, and suppression strategies on anxious arousal. Behaviour Research and Therapy, 47(5), 389-394. https://doi.org/10.1016/j.brat.2009.02. 010.

Huffziger, S., \& Kuehner, C. (2009). Rumination, distraction, and mindful self-focus in depressed patients. Behaviour Research and Therapy, 47(3), 224-230. https://doi.org/10.1016/j.brat.2008.12. 005.

Hyland, T. (2016). Mindful nation UK - report by the mindfulness allparty parliamentary group (MAPPG). Journal of Vocational Education \& Training, 68(1), 133-136. https://doi.org/10.1080/ 13636820.2015.1123926. 
Jenkins, K. T., \& Tapper, K. (2013). Resisting chocolate temptation using a brief mindfulness strategy. British Journal of Health Psychology, 1-14. https://doi.org/10.1111/bjhp.12050.

Jenkins, K. T., \& Tapper, K. (2014). Resisting chocolate temptation using a brief mindfulness strategy. British Journal of Health Psychology, 19(3), 509-522. https://doi.org/10.1111/bjhp.12050.

Johns, S. A., Brown, L. F., Beck-Coon, K., Monahan, P. O., Tong, Y., \& Kroenke, K. (2015). Randomized controlled pilot study of mindfulness-based stress reduction for persistently fatigued cancer survivors. Psycho-Oncology, 24(8), 885-893. https://doi.org/10. 1002/pon.3648.

Johnson, S., Gur, R. M., David, Z., \& Currier, E. (2015). One-session mindfulness meditation: a randomized controlled study of effects on cognition and mood. Mindfulness, 6(1), 88-98. https://doi.org/10. 1007/s12671-013-0234-6.

Kabat-Zinn, J. (2006). Mindfulness-based interventions in context: past, present, and future. Clinical Psychology: Science and Practice, 10(2), 144-156. https://doi.org/10.1093/clipsy.bpg016.

Keng, S.-L., \& Tan, H. H. (2018). Effects of brief mindfulness and loving-kindness meditation inductions on emotional and behavioral responses to social rejection among individuals with high borderline personality traits. Behaviour Research and Therapy, 100, 44-53. https://doi.org/10.1016/j.brat.2017.11.005.

Krolikowski, A. M. (2013). The effectiveness of internet-based mindfulness interventions for physical and mental illnesses. International Journal of Cyber Behavior, Psychology and Learning, 3(4), 84-96. https://doi.org/10.4018/ijcbpl.2013100106.

Kuehner, C., Huffziger, S., \& Liebsch, K. (2009). Rumination, distraction and mindful self-focus: effects on mood, dysfunctional attitudes and cortisol stress response. Psychological Medicine, 39(2), 219-228. https://doi.org/10.1017/S0033291708003553.

Lai, C., MacNeil, B., \& Frewen, P. (2015). A comparison of the attentional effects of single-session mindfulness meditation and Fp-HEG neurofeedback in novices. Mindfulness, 6(5), 1012-1020. https:// doi.org/10.1007/s12671-014-0347-6.

Lakhan, S. E., \& Schofield, K. L. (2013). Mindfulness-based therapies in the treatment of somatization disorders: a systematic review and meta-analysis. PLoS One, 8(8), e71834. https://doi.org/10.1371/ journal.pone.0071834.

Lancaster, S. L., Klein, K. P., \& Knightly, W. (2016). Mindfulness and relaxation: a comparison of brief, laboratory-based interventions. Mindfulness, 7(3), 614-621. https://doi.org/10.1007/s12671-0160496-X.

Lebois, L. A. M., Papies, E. K., Gopinath, K., Cabanban, R., Quigley, K. S., Krishnamurthy, V., et al. (2015). A shift in perspective: decentering through mindful attention to imagined stressful events. Neuropsychologia, 75, 505-524. https://doi.org/10.1016/j. neuropsychologia.2015.05.030.

Lee, J. K., \& Orsillo, S. M. (2014). Investigating cognitive flexibility as a potential mechanism of mindfulness in generalized anxiety disorder. Journal of Behavior Therapy and Experimental Psychiatry, 45(1), 208-216. https://doi.org/10.1016/j.jbtep.2013.10.008.

Liu, X., Chang, S., Chen, W., Si, M., \& S, W. (2013). Effect of brief mindfulness intervention on tolerance and distress of pain induced by cold-pressor task. Stress and Health, 29, 199-204.

Liu, X., Wang, S., Chang, S., Chen, W., \& Si, M. (2012). Effect of brief mindfulness intervention on tolerance and distress of pain induced by cold-pressor task. Stress and Health, 29(3), 199-204. https://doi. org $/ 10.1002 / \mathrm{smi} .2446$

Luberto, C. M., \& McLeish, A. C. (2018). The effects of a brief mindfulness exercise on state mindfulness and affective outcomes among adult daily smokers. Addictive Behaviors, 77, 73-80. https://doi.org/ 10.1016/j.addbeh.2017.09.013.

Lutz, A., McFarlin, D. R., Perlman, D. M., Salomons, T. V., \& Davidson, R. J. (2013). Altered anterior insula activation during anticipation and experience of painful stimuli in expert meditators. NeuroImage, 64, 538-546. https://doi.org/10.1016/j.neuroimage.2012.09.030.

Lutz, J., Herwig, U., Opialla, S., Hittmeyer, A., Jäncke, L., Rufer, M., ... Brühl, A. B. (2014). Mindfulness and emotion regulation-an fMRI study. Social Cognitive and Affective Neuroscience, 9(6), 776-785. https://doi.org/10.1093/scan/nst043

Marek, R. J., Ben-Porath, D. D., Federici, A., Wisniewski, L., \& Warren, M. (2013). Targeting premeal anxiety in eating disordered clients and normal controls: a preliminary investigation into the use of mindful eating vs. distraction during food exposure. The International Journal of Eating Disorders, 46(6), 582-585. https:// doi.org/10.1002/eat.22152.

May, J., Andrade, J., Batey, H., Berry, L.-M., \& Kavanagh, D. J. (2010). Less food for thought. Impact of attentional instructions on intrusive thoughts about snack foods. Appetite, 55(2), 279-287. https://doi. org/10.1016/j.appet.2010.06.014.

McClintock, A. S., \& Anderson, T. (2015). The application of mindfulness for interpersonal dependency: effects of a brief intervention. Mindfulness, 6(2), 243-252. https://doi.org/10.1007/s12671-0130253-3.

McHugh, L., \& Wood, R. (2013). Stimulus over-selectivity in temporal brain injury: mindfulness as a potential intervention. Brain Injury, 27(13-14), 1595-1599. https://doi.org/10.3109/02699052.2013. 834379.

Metcalfe, R. K., Fitzpatrick, S., \& Kuo, J. R. (n.d.). A laboratory examination of emotion regulation skill strengthening in borderline personality disorder emotional intensity and reactivity in BPD. https:// doi.org/10.1037/per0000156.

Moher, D., Liberati, A., Tetzlaff, J., Altman, D. G., \& PRISMA Group, T. P. (2009). Preferred reporting items for systematic reviews and metaanalyses: the PRISMA statement. PLoS Medicine, 6(7), e1000097. https://doi.org/10.1371/journal.pmed.1000097.

Nasser, J. D., \& Przeworski, A. (2017). A comparison of two brief present moment awareness training paradigms in high worriers. Mindfulness, 8(3), 775-787. https://doi.org/10.1007/s12671-0160656-z.

Papies, E. K., Barsalou, L. W., \& Custers, R. (2012). Mindful attention prevents mindless impulses. Social Psychological and Personality Science, 3(3), 291-299. https://doi.org/10.1177/ 1948550611419031.

Papies, E. K., Pronk, T. M., Keesman, M., \& Barsalou, L. W. (2015). The benefits of simply observing: mindful attention modulates the link between motivation and behavior. Journal of Personality and Social Psychology, 108(1), 148-170. https://doi.org/10.1037/a0038032.

Park, J., Lyles, R. H., \& Bauer-Wu, S. (2014). Mindfulness meditation lowers muscle sympathetic nerve activity and blood pressure in African-American males with chronic kidney disease. American Journal of Physiology. Regulatory, Integrative and Comparative Physiology, 307(1), R93-R101. https://doi.org/10.1152/ajpregu. 00558.2013.

Pepping, C. A., Davis, P. J., \& O’Donovan, A. (2015). The association between state attachment security and state mindfulness. PLoS One, 10(3), 1-12. https://doi.org/10.1371/journal.pone.0116779.

Perkins-Porras, L., Riaz, M., Okekunle, A., Zhelezna, S., Chakravorty, I., \& Ussher, M. (2018). Feasibility study to assess the effect of a brief mindfulness intervention for patients with chronic obstructive pulmonary disease: a randomized controlled trial. Chronic Respiratory Disease. https://doi.org/10.1177/1479972318766140.

Pinto-Gouveia, J., Duarte, C., Matos, M., \& Fráguas, S. (2014). The protective role of self-compassion in relation to psychopathology symptoms and quality of life in chronic and in cancer patients. Clinical Psychology \& Psychotherapy, 21(4), 311-323. https://doi. org/10.1002/cpp.1838.

Rogojanski, J., Vettese, L. C., \& Antony, M. M. (2011). Coping with cigarette cravings: comparison of suppression versus mindfulness- 
based strategies. Mindfulness, 2(1), 14-26. https://doi.org/10.1007/ s12671-010-0038-x.

Scherpiet, S., Herwig, U., Opialla, S., Scheerer, H., Habermeyer, V., Jäncke, L., \& Brühl, A. B. (2015). Reduced neural differentiation between self-referential cognitive and emotional processes in women with borderline personality disorder. Psychiatry Research: Neuroimaging, 233(3), 314-323. https://doi.org/10.1016/j. pscychresns.2015.05.008.

Schofield, T. P., Creswell, J. D., \& Denson, T. F. (2015). Brief mindfulness induction reduces inattentional blindness. Consciousness and Cognition, 37, 63-70. https://doi.org/10.1016/j.concog.2015.08. 007.

Sharpe, L., Nicholson Perry, K., Rogers, P., Refshauge, K., \& Nicholas, M. K. (2013). A comparison of the effect of mindfulness and relaxation on responses to acute experimental pain. European Journal of Pain, 17(5), 742-752. https://doi.org/10.1002/j.1532-2149.2012. 00241.x

Singer, A. R., \& Dobson, K. S. (2007). An experimental investigation of the cognitive vulnerability to depression. Behaviour Research and Therapy, 45(3), 563-575. https://doi.org/10.1016/j.brat.2006.05. 007.

Spielberger, C., Gorsuch, R., \& Lushene, R. (1970). Manual for the StateTrait Anxiety Inventory (STAI). Palo Alto: Consulting Psychologists Press.

Steffen, P. R., \& Larson, M. J. (2014). A brief mindfulness exercise reduces cardiovascular reactivity during a laboratory stressor paradigm. Mindfulness, 5, 803-811. https://doi.org/10.1007/s12671014-0320-4

Strauss, C., Cavanagh, K., Oliver, A., Pettman, D., \& Taylor, R. (2014). Mindfulness-based interventions for people diagnosed with a current episode of an anxiety or depressive disorder: a meta-analysis of randomised controlled trials. PLoS One, 9(4), e96110. https://doi. org/10.1371/journal.pone.0096110.

Stroebele, N., De Castro, J. M., Stuht, J., Catenacci, V., Wyatt, H. R., \& Hill, J. O. (n.d.). A small-changes approach reduces energy intake in free-living humans. Journal of the American College of Nutrition, $28,63-68$.

Swain, N. R., \& Trevena, J. (2014). A comparison of therapist-present or therapist-free delivery of very brief mindfulness and hypnosis for acute experimental pain. New Zealand Journal of Psychology, 43(3), 22-28.

Szasz, P. L., Szentagotai, A., \& Hofmann, S. G. (2011). The effect of emotion regulation strategies on anger. Behaviour Research and Therapy, 49(2), 114-119. https://doi.org/10.1016/j.brat.2010.11. 011.

Szasz, P. L., Szentagotai, A., \& Hofmann, S. G. (2012). Effects of emotion regulation strategies on smoking craving, attentional bias, and task persistence. Behaviour Research and Therapy, 50(5), 333-340. https://doi.org/10.1016/j.brat.2012.02.010.

Szasz, P. L., Hofmann, S. G., Heilman, R. M., \& Curtiss, J. (2016). Effect of regulating anger and sadness on decision-making. Cognitive Behaviour Therapy, 45(6), 479-495. https://doi.org/10.1080/ 16506073.2016.1203354.

Teasdale, J. D., Segal, Z. V., Williams, J. M., Ridgeway, V. A., Soulsby, J. M., \& Lau, M. A. (2000). Prevention of relapse/recurrence in major depression by mindfulness-based cognitive therapy. Journal of Consulting and Clinical Psychology, 68(4), 615-623.

Tincher, M. M., Lebois, L. A. M., \& Barsalou, L. W. (2016). Mindful attention reduces linguistic intergroup bias. Mindfulness, 7(2), 349 360. https://doi.org/10.1007/s12671-015-0450-3.

Troy, A. S., Shallcross, A. J., Brunner, A., Friedman, R., \& Jones, M. C. (2018). Cognitive reappraisal and acceptance: effects on emotion, physiology, and perceived cognitive costs. Emotion, 18(1), 58-74. https://doi.org/10.1037/emo0000371.

Ussher, M., Cropley, M., Playle, S., Mohidin, R., \& West, R. (2009). Effect of isometric exercise and body scanning on cigarette cravings and withdrawal symptoms. Addiction, 104(7), 1251-1257. https:// doi.org/10.1111/j.1360-0443.2009.02605.x .

Ussher, M., Spatz, A., Copland, C., Nicolaou, A., Cargill, A., AminiTabrizi, N., \& McCracken, L. M. (2012). Immediate effects of a brief mindfulness-based body scan on patients with chronic pain. Journal of Behavioral Medicine, 37(1), 127-134. https://doi.org/10. 1007/s10865-012-9466-5.

Wade, T., George, W. M., \& Atkinson, M. (2009). A randomized controlled trial of brief interventions for body dissatisfaction. Journal of Consulting and Clinical Psychology, 77(5), 845-854. https://doi. org/10.1037/a0016879.

Wenk-Sormaz, H. (2005). Meditation can reduce habitual responding. Advances in Mind-Body Medicine, 21(3-4), 33-49.

Westbrook, C., Creswell, J. D., Tabibnia, G., Julson, E., Kober, H., \& Tindle, H. A. (2013). Mindful attention reduces neural and selfreported cue-induced craving in smokers. Social Cognitive and Affective Neuroscience, 8(1), 73-84. https://doi.org/10.1093/scan/ nsr076.

Westenberg, R. F., Zale, E. L., Heinhuis, T. J., Özkan, S., Nazzal, A., Lee, S.-G., et al. (2018). Does a brief mindfulness exercise improve outcomes in upper extremity patients? A randomized controlled trial. Clinical Orthopaedics and Related Research, 476(4), 790-798. https://doi.org/10.1007/s11999.0000000000000086.

Wilson, C. J., Barnes-Holmes, Y., \& Barnes-Holmes, D. (2014). The effect of emotion regulation strategies on physiological and selfreport measures of anxiety during a stress-inducing academic task. International Journal of Psychology and Psychological Therapy, 14(1), 1-15.

Wolgast, M., Lundh, L.-G., \& Viborg, G. (2011). Cognitive reappraisal and acceptance: an experimental comparison of two emotion regulation strategies. Behaviour Research and Therapy, 49(12), 858866. https://doi.org/10.1016/j.brat.2011.09.011.

Zeidan, F., Gordon, N. S., Merchant, J., \& Goolkasian, P. (2010a). The effects of brief mindfulness meditation training on experimentally induced pain. The Journal of Pain, 11(3), 199-209. https://doi.org/ 10.1016/j.jpain.2009.07.015

Zeidan, F., Johnson, S. K., Gordon, N. S., \& Goolkasian, P. (2010b). Effects of brief and sham mindfulness meditation on mood and cardiovascular variables. Journal of Alternative and Complementary Medicine (New York, N.Y.), 16(8), 867-873. https://doi.org/10.1089/acm.2009.0321.

Zeidan, F., Johnson, S. K., Diamond, B. J., David, Z., \& Goolkasian, P. (2010c). Mindfulness meditation improves cognition: evidence of brief mental training. Consciousness and Cognition, 19(2), 597605. https://doi.org/10.1016/j.concog.2010.03.014.

Zeidan, F., Martucci, K. T., Kraft, R. a., Gordon, N. S., McHaffie, J. G., \& Coghill, R. C. (2011). Brain mechanisms supporting the modulation of pain by mindfulness meditation. The Journal of Neuroscience, 31(14), 5540-5548. https://doi.org/10.1523/JNEUROSCI.5791-10. 2011 .

Zeidan, F., Emerson, N. M., Farris, S. R., Ray, J. N., Jung, Y., McHaffie, J. G., \& Coghill, R. C. (2015). Mindfulness meditation-based pain relief employs different neural mechanisms than placebo and sham mindfulness meditation-induced analgesia. Journal of Neuroscience, 35(46), 15307-15325. https://doi.org/10.1523/ JNEUROSCI.2542-15.2015.

Publisher's Note Springer Nature remains neutral with regard to jurisdictional claims in published maps and institutional affiliations. 